\title{
A SENSITIVITY STUDY OF LIRIC ALGORITHM TO USER-DEFINED INPUT PARAMETERS, USING SELECTED CASES FROM THESSALONIKI'S MEASUREMENTS
}

\author{
Filioglou M. ${ }^{1,2 *}$, Balis D. ${ }^{1}$, Siomos, N. ${ }^{1}$, Poupkou, A. ${ }^{1}$, Dimopoulos, S. ${ }^{1}$, Chaikovsky, A. ${ }^{3}$ \\ ${ }^{1}$ Laboratory of Atmospheric Physics, Aristotle University of Thessaloniki, Greece \\ ${ }^{2}$ Finnish Meteorological Institute, Atmospheric Research Center of Eastern Finland, Kuopio, Finland \\ ${ }^{3}$ Institute of Physics, National Academy of Science, Minsk, Belarus \\ *Email:_mfiliogl@physics.auth.gr,maria.filioglou@fmi.fi
}

\begin{abstract}
A targeted sensitivity study of the LIRIC algorithm was considered necessary to estimate the uncertainty introduced to the volume concentration profiles, due to the arbitrary selection of user-defined input parameters. For this purpose three different tests were performed using Thessaloniki's Lidar data. Overall, tests in the selection of the regularization parameters, an upper and a lower limit test were performed. The different sensitivity tests were applied on two cases with different predominant aerosol types, a dust episode and a typical urban case.
\end{abstract}

\section{INTRODUCTION}

The LIdar Radiometer Inversion Code (LIRIC) has been developed within ACTRIS by the Institute of Physics in Minsk (Belarus) in collaboration with the Laboratoire d'Optique Atmosphérique in Lille, (France). LIRIC combines active and passive remote sensing techniques from two different instruments, a Lidar and a Cimel sunphotometer. In this work, measurements from the multiwavelength RamanLidar and the Cimel sunphotometer which are located at the Laboratory of Atmospheric Physics (LAP) in Aristotle University of Thessaloniki (AUTH), (Greece), $\left(40.6^{\circ} \mathrm{N}, 22.9^{\circ} \mathrm{E}, 60 \mathrm{~m}\right.$ a.s.l) are being used. The three elastic backscatter channels $(355,532,1064 \mathrm{~nm})$ along with the column volume concentration derived by the sunphotometer paired to produce profiles of fine and coarse mode concentrations. If a depolarization channel is added, a further distinction in spheroid and spherical mode is possible. A detailed description of LIRIC can be found here [2] [4] [6].

The sensitivity tests were applied on two different cases. The first one is a typical urban pollution case detected at Thessaloniki on the $14^{\text {th }}$ of January 2014 and the second corresponds to a Saharan dust episode captured on the $20^{\text {th }}$ of January 2014 by the Lidar system.

\section{METHODOLOGY}

The main outputs of the algorithm are concentration profiles of fine and coarse mode expressed in parts per billion (ppbv). These concentrations were converted to $\mu \mathrm{gr} / \mathrm{m}^{3}$ so as to obtain comparable to the models' output data [5].

Firstly, a Regularization parameters test was performed for each case so as to determine the deviations on the retrieved quantities and also to conclude to a proper set of parameters for the rest of the retrievals. Once concluded to a proper set of parameters, an Upper limit test was performed continued by a Lower limit test.

The regularization parameters consist of 3 different sets referring to Lidar, sunphotometer and smoothness restrains. Smoothness parameters were remained unchanged while the others varied according to Table 1 . More than 1800 possible combinations between these orders of magnitude where performed so as to evaluate the uncertainties introduced to the results. A succeeded retrieval was considered as the one where each signal's AOD output did not differ more than $5 \%$ of the AERONET's AOD and in addition the column integrated volume concentrations did not differ more than $5 \%$ of the 
AERONET's one. The Upper limit test was performed by cutting the signal at three different heights above the ref. height ( $\sim 500 \mathrm{~m}$ above) while in the Lower limit test a step of $\pm 200 \mathrm{~m}$ was applied above/below the height of the full overlap. Each test was done separately so as to determine correctly the deviations occurred. Errors were calculated by averaging the arising signals.

The photochemical model CAMx [3] has been used for the vertical concentration profiles of fine mode and the BSC-DREAM8b v2.0 [1] web based model for the comparison of the coarse mode.

Table 1: Range of Regularization Parameters.

\begin{tabular}{|c|c|c|}
\hline & Parameter & Range \\
\hline \multirow{3}{*}{ Lidar } & $\mathrm{k}_{355}$ & from $10^{-6}$ to $10^{-3}$ \\
\cline { 2 - 3 } & $\mathrm{k}_{532}$ & from $10^{-6}$ to $10^{-3}$ \\
\cline { 2 - 3 } & $\mathrm{k}_{1064}$ & from $10^{-6}$ to $10^{-3}$ \\
\hline \multirow{2}{*}{ Cimel } & $\mathrm{f}_{\text {fine }}$ & from $10^{-1}$ to $10^{3}$ \\
\cline { 2 - 3 } & $\mathrm{f}_{\text {coarse }}$ & from $10^{-1}$ to $10^{3}$ \\
\hline Smooth & $\mathrm{d}_{\text {fine }}, \mathrm{d}_{\text {coarse }}$ & 2 \\
\hline
\end{tabular}

\section{RESULTS}

Table 2: Overview of input parameters and tests performed

\begin{tabular}{|r|c|c|}
\hline & Urban case & Dust case \\
\hline $\mathbf{Z}_{\mathbf{L}}(\mathbf{m}):$ & 975 & 1005 \\
\hline $\mathbf{Z}_{\mathbf{R H}}(\mathbf{m}):$ & 3450 & 4950 \\
\hline $\mathbf{Z}_{\mathbf{U}}(\mathbf{m}):$ & 3600 & 5100 \\
\hline $\mathbf{k}_{\mathbf{3 5 5} 5}:$ & $9 * 10^{-5}$ & $2 * 10^{-4}$ \\
\hline $\mathbf{k}_{\mathbf{5 3 2}}:$ & $5 * 10^{-4}$ & $2 * 10^{-4}$ \\
\hline $\mathbf{k}_{\mathbf{1 0 6 4}}:$ & $4 * 10^{-4}$ & $9 * 10^{-5}$ \\
\hline $\mathbf{f}_{\text {fine }}:$ & 5 & 1 \\
\hline $\mathbf{f}_{\text {coarse }}:$ & 0.7 & 5 \\
\hline
\end{tabular}

The overall input parameters for the two cases are summarized in Table 2. Each of the following figures show the mean profile with one standard deviation which was calculated by averaging the arising available signals (e.g. for the upper/lower limit tests there were three arising signals (three different cuts as described above)).

Case I: 13 January 2014

a) Regularization parameters test
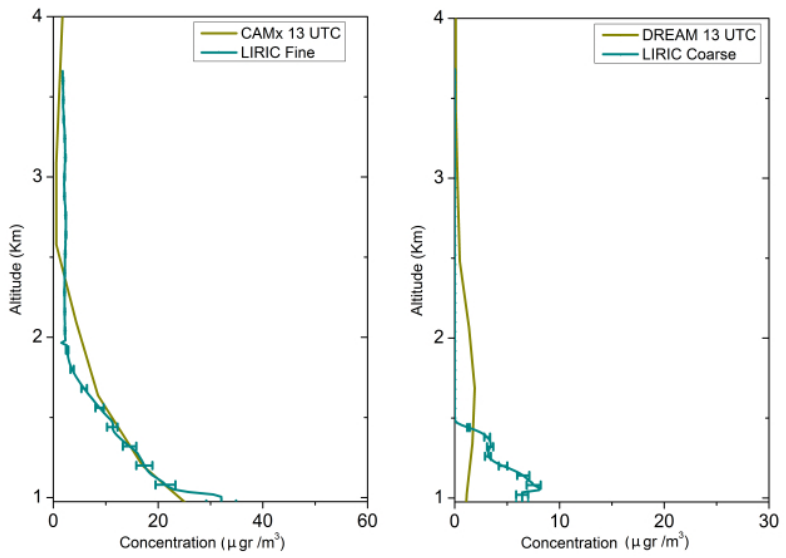

Figure 1: Mean profiles and standard deviations of fine and coarse mode derived by LIRIC (cyan) compared with models (dark yellow) for 13th January 2014.

b) Upper Limit test
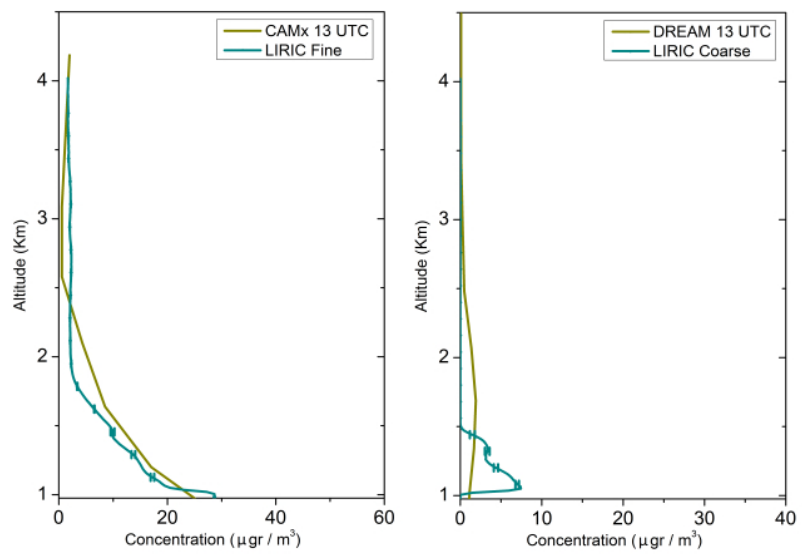

Figure 2: Respective results when varying the Upper limit height for $13^{\text {th }}$ January case. 
c) Lower limit test
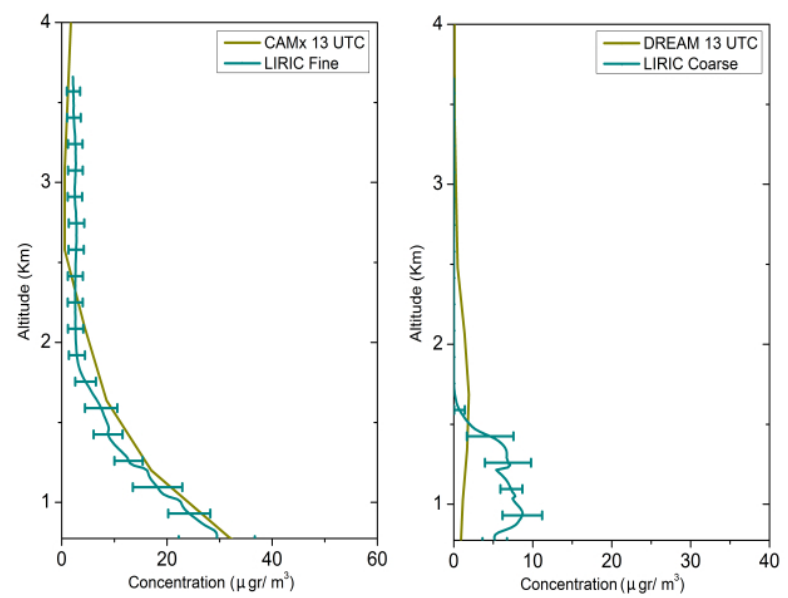

Figure 3: Respective results when varying the Lower limit height for $13^{\text {th }}$ January case.

Case II: 20 January 2014

a) Regularization parameters test
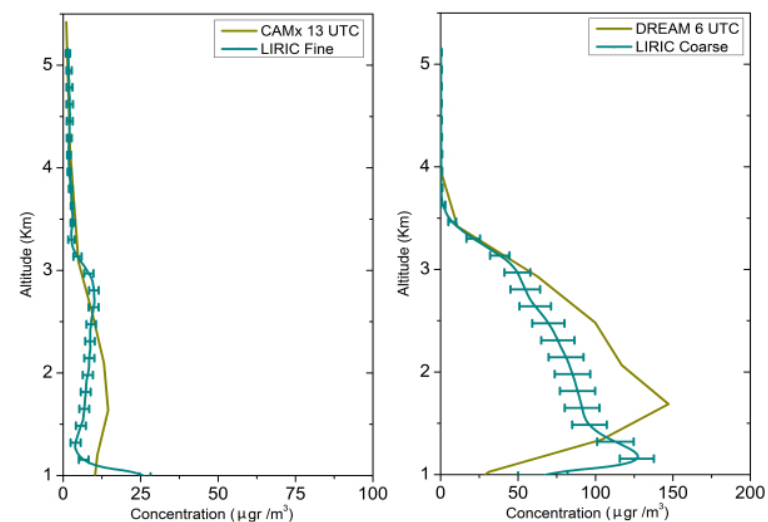

Figure 4: Respective results for the dust event occurred at 20 Jan. 2014.

b) Upper Limit test
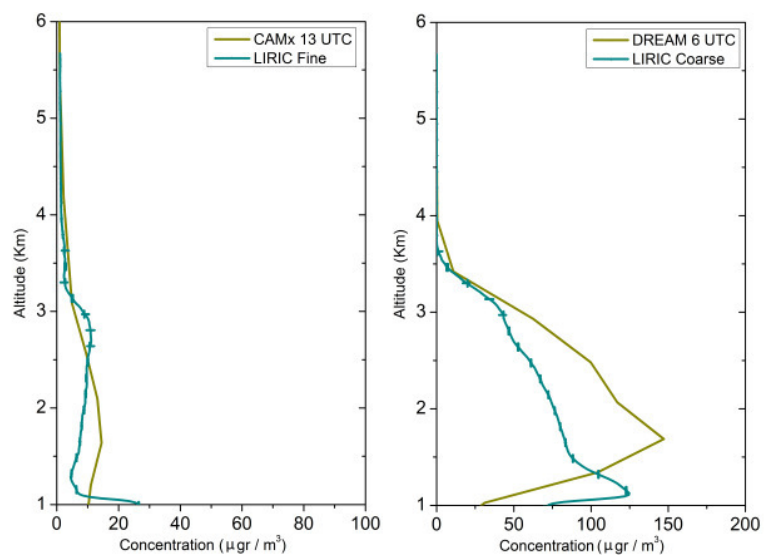

Figure 5: Respective results when varying the Upper Limit height for $20^{\text {th }}$ January case. c) Lower limit test
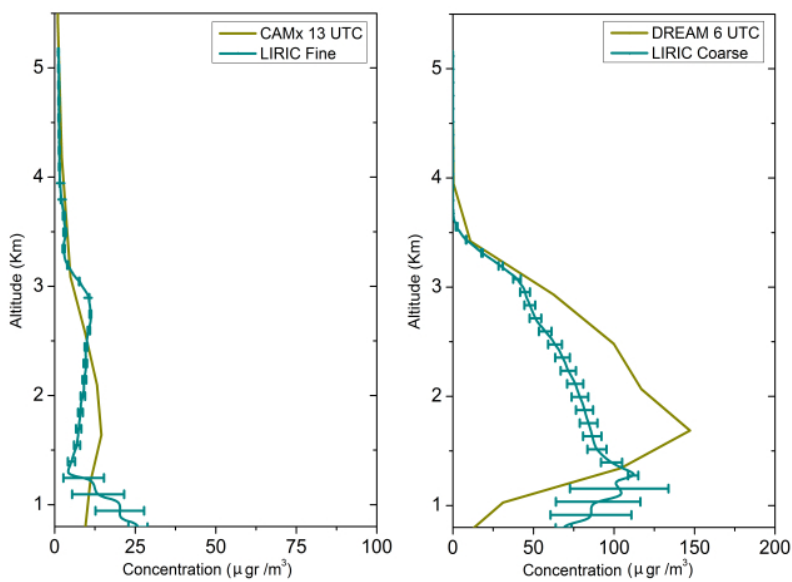

Figure 6: Respective results when varying the Lower Limit height for $20^{\text {th }}$ January case.

\section{CONCLUSIONS}

The arbitrary selection of the regularization parameters test introduces an uncertainty of $10 \%$ in the lower part and $2.5 \%$ in the upper part of the concentration profiles, when examining a typical urban aerosol case. The uncertainty due to the choice of the Lower limit ranged between 25-30\% in the lower part for both modes and $40 \%$ for the fine mode in the upper part.

For the dust case, the uncertainty introduced by the choice of the regularization parameters is larger and ranged between $10-30 \%$ below $3 \mathrm{~km}$ and decreases further above. The uncertainties due to the lower limit selection ranged above $30 \%$ in the lower part for both modes (at some heights reached $80 \%$ ).

The upper limit selection introduced $1 \%$ variation at both cases.

Good structural agreement between CAMx and LIRIC was found in both cases for the fine mode. Good structural agreement for DREAM and LIRIC was found for the dust case, though there are differences in the height of the maximum concentration.

\section{ACKNOWLEDGEMENTS}

Special thanks to A. Chaikovsky and the associate team for providing LIRIC publicly. The algorithm has been developed within ACTRIS project. The 
ground-based EARLINET LIDAR database has been downloaded from www.earlinet.org .

\section{REFERENCES}

[1] Basart, S., Pérez, C., Nickovic, S., Cuevas, E. \& Baldasano, J.M.: Development and evaluation of the BSC-DREAM8b dust regional model over Northern Africa, the Mediterranean and the Middle East. Tellus B, 64, 1-23, 2012.

[2] Chaikovsky A., Dubovik O., Goloub P., Tanré D., Pappalardo G., Wandinger U., Chaikovskaya L., Denisov S., Grudo Y., Lopatsin A., Karol Y., Lapyonok T., Korol M., Osipenko F., Savitski D., Slesar A., Apituley, A., Arboledas L. A., Binietoglou I., Kokkalis P., Granados Muñoz M. J., Papayannis A., Perrone M. R., Pietruczuk A., Pisani G., Rocadenbosch F., Sicard M., De Tomasi F., Wagner, J., and Wang X.: Algorithm and software for the retrieval of vertical aerosol properties using combined lidar/radiometer data: Dissemination in EARLINET, Reviewed and revised papers presented at the 26th International Laser Radar Conference, Porto Heli, Greece, 399-402, 2012.

[3] ENVIRON. User's Guide to the Comprehensive Air Quality Model with Extensions (CAMx) Version 6.10. ENVIRON International Corporation, 101 Rowland Way, Suite 220, Novato, California 949455010, 2014.

[4] Granados-Muñoz M. J., Guerrero-Rascado J. L., Bravo-Aranda J. A., Navas-Guzmá, F. , Valenzuela A., Lyamani H., Chaikovsky A., Wandinger U., Ansmann A., Dubovik O., Grudo J. O., AladosArboledas L.: Retrieving aerosol microphysical properties by LIdar-Radiometer Inversion Code (LIRIC) for different aerosol types. Journal of Geophysical Research Atmospheres 04/2014; 119(8), 2014.

[5] Kokkalis P., A. Papayannis, V. Amiridis, R. E. Mamouri, I. Veselovskii, A. Kolgotin, G. Tsaknakis, N. I. Kristiansen, A. Stohl, and L. Mona: Optical, microphysical, mass and geometrical properties of aged volcanic particles observed over Athens, Greece, during the Eyjafjallajökull eruption in April 2010 through synergy of Raman Lidar and sunphotometer measurements. Atmos. Chem. Phys., 13, 9303-9320, 2013.

[6] Wagner, J., Ansmann, A., Wandinger, U., Seifert, P., Schwarz, A., Tesche, M., Chaikovsky, A., and Dubovik, O.: Evaluation of the
Lidar/Radiometer Inversion Code (LIRIC) to determine microphysical properties of volcanic and desert dust, Atmos. Meas. tech., 6, 1707-1724, doi:10.5194/amt-6-1707-2013, 2013. 